\title{
Phytoplankton drives nitrite dynamics in the Gulf of Aqaba, Red Sea
}

\author{
Mutaz Al-Qutob ${ }^{1,2, *}$, Clivia Häse ${ }^{3,4}$, Max M. Tilzer ${ }^{5}$, Boaz Lazar $^{6,7}$ \\ ${ }^{1}$ Department of Biology, Faculty of Science and Technology, Alquds University, Palestinian Authority \\ ${ }^{2}$ Department of Life Sciences, Bar Ilan University, Ramat Gan, Israel \\ ${ }^{3}$ Center for Tropical Marine Ecology-ZMT, Fahrenheitstraße 6, Bremen, 28359 Bremen, Germany \\ ${ }^{4}$ German Aerospace Center-DLR Oberpfaffenhofen, 82230 Wessling, Germany \\ ${ }^{5}$ Aquatic Ecology, University of Constance, 78457 Konstanz, Germany \\ ${ }^{6}$ Institute of Earth Sciences and ${ }^{7}$ Moshe Shilo Centre for Marine Biogeochemistry, The Hebrew University of Jerusalem, \\ Givat Ram, 91904 Jerusalem, Israel
}

\begin{abstract}
This study focuses on the seasonal changes in the Gulf of Aquaba, Red Sea, in nitrite concentration and their relationship with phytoplankton activity, which is mainly controlled by an alternation of water-column stratification with vertical mixing. Within the euphotic zone, during thermal summer stratification, nutrient depletion was severe, and no nitrite could be detected in the upper $70 \mathrm{~m}$. However, during stratification, nitrite was always associated with the nutriclines and formed a deep maximum at the bottom of the euphotic zone. In contrast, nitrite accumulated in the mixed water column during winter, closely paralleling the development of phytoplankton biomass. In the Gulf of Aqaba, maximum nitrite accumulation occurred when winter mixing reached its greatest depth, which in turn was coincident with the height of the phytoplankton spring bloom. Thus, our field data suggest that accumulation of nitrite is associated with nutrient-stimulated phytoplankton growth. This hypothesis was supported by nutrient-enrichment bioassays performed concomitantly: only when phytoplankton growth was stimulated by nutrient additions, did nitrite accumulate in the water. In the bioassays, the time-course of nitrite accumulation closely paralleled the development of phytoplankton biomass during the incubation period. We therefore suggest that the accumulation of nitrite in the mixed water column during winter is due to excretion by algal cells. Our field and experimental data show that between 10 and $15 \%$ of the total amount of nitrogen entering the mixed-water column is released as nitrite by phytoplankton. Further, our field and experimental data support the hypothesis that nitrite excretion by phytoplankton has a significant role in the formation of the deep nitrite maximum (DNM) during stratification in summer. In the bioassays, phytoplankton cells excreted nitrite even when ammonia was the nitrogen source. This indicates a so far unrecognised physiological pathway involved in nitrite excretion by phytoplankton cells.
\end{abstract}

KEY WORDS: Nutrients $\cdot$ Nitrogen species $\cdot$ Nitrite $\cdot$ Phytoplankton

Resale or republication not permitted without written consent of the publisher

\section{INTRODUCTION}

Nitrite plays an intermediate role in several biological processes within the oceanic nitrogen cycle, being the net result of different generation and consumption processes (Rakestraw 1936, Vaccaro \& Ryther 1960).

${ }^{*}$ Present address: Department of Life Sciences, Bar Ilan University, Ramat Gan, Israel. E-mail: qutob@planet.edu
Surface or subsurface nitrite maxima occur over wide areas of the tropical and temperate oceans. In a stratified water column, the nitrite maximum is found near the bottom of the euphotic zone or, at higher latitudes, often throughout the upper mixed layer (Dore \& Karl $1996 \mathrm{a}, \mathrm{b})$. In upwelling regions, or as a result of the introduction of nitrate into the euphotic zone by vertical winter mixing, the nitrite concentrations can increase remarkably (Rakestraw 1936, Olson 1981a,b, Dore \& Karl 1996a). 
In the well-oxygenated water column of the Gulf of Aqaba, the dissimilatory reduction of nitrate to nitrite by denitrifying bacteria is likely to be negligible. Thus, we consider the following processes as potentially responsible for the generation and consumption of ambient nitrite in the Gulf of Aqaba: (1) Excretion of nitrite during nitrate reduction, i.e. incomplete assimilatory reduction of nitrate by phytoplankton and bacteria (Vaccaro \& Ruyther 1960, Wada \& Hattori, 1971, Miyazzaki et al. 1973, Miyazzaki et al. 1975, Kiefer et al. 1976, Herbland \& Voituriez 1979, Olson 1981a, Dore \& Karl, 1996b, Collos 1998). (2) Ammonium oxidation to nitrite by autotrophic nitrifying bacteria (Brandhorst 1959, Miyazzaki et al. 1975, Olson 1981a,b, Ward 1986, Dore \& Karl 1996b, Enoksson et al. 1996). (3) Nitrite assimilation by phytoplankton and bacteria (Ward et al. 1989). (4) Nitrite oxidation to nitrate by autotrophic nitrifying bacteria (Ward et al. 1989, Dore \& Karl 1996b).

Light is known to have a stimulating effect on phytoplankton nitrite excretion during nitrate assimilation (Wada \& Hattori 1971), and an inhibitory effect on both ammonium oxidation and nitrite oxidation by nitrifying bacteria (Horrigan et al. 1981, Olson, 1981a,b, Guerrero \& Jones 1996).

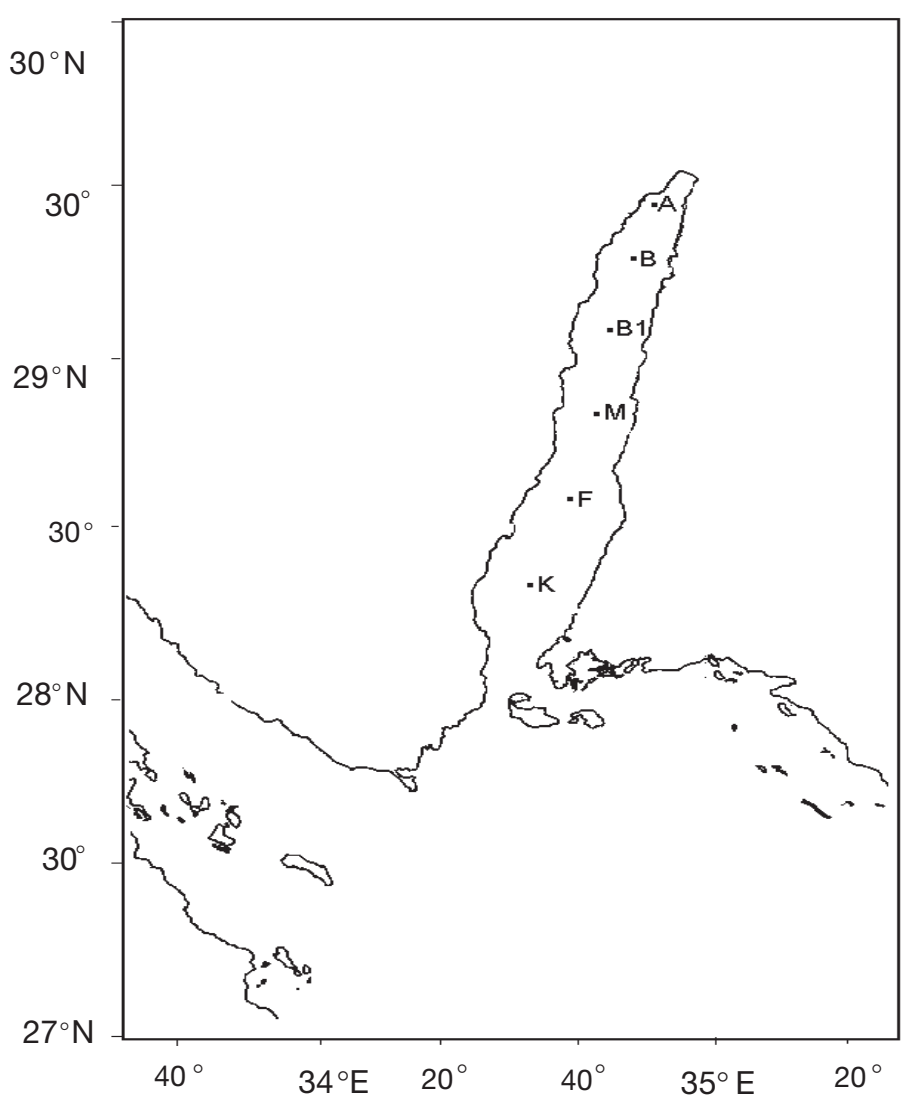

Fig. 1. Gulf of Aqaba and the northern Red Sea, showing Stns A to K in the Gulf
The majority of the studies on nitrite dynamics focus on the deep nitrite maximum in a stratified water column (e.g. Wada \& Hattori 1971, Kiefer et al. 1976, Zafiriou et al. 1992, Dore \& Karl 1996a,b). The formation of the Deep Nitrite Maximum (DNM) is related to the vertical separation of generation and consumption processes in the water column driven by differential sensitivity to light (Wada \& Hattori 1971, Olson 1981a,b, Dore \& Karl 1996b). Only a few studies have reported on nitrite accumulation within a mixed water column (e.g. Lipschultz et al. 1996, Collos 1998), although nitrite excretion by phytoplankton is well documented for both cultures and natural populations (Wada \& Hattori 1971, Collos 1998).

The present study was conducted in the oligotrophic Gulf of Aqaba at the northern end of the Red Sea. The Gulf, which is located on the fault of the major riftvalley system, is $165 \mathrm{~km}$ long and an average of $15 \mathrm{~km}$ wide. The maximum depth is $1830 \mathrm{~m}$, the average depth is around $800 \mathrm{~m}$. The Gulf of Aqaba receives nutrient-depleted surface waters from the Indian Ocean through the Gulf of Aden across 2 shallow sills: the Bab al Mandab (ca. $140 \mathrm{~m}$ deep), and, $2000 \mathrm{~km}$ to the north, the Straits of Tiran (ca. $250 \mathrm{~m}$ deep). The Gulf is surrounded by a sparsely inhabited desert and therefore has characteristics that are typical for warm oceanic open waters. It is thus an ideal site for studying nutrient cycling in an oligotrophic ocean. Within the euphotic zone nutrients are depleted almost throughout the year. The vertical distribution of nutrients and phytoplankton in the Gulf of Aqaba is mainly controlled by an annual cycle of stratification in summer and deep mixing in winter. The latter is far deeper in the Gulf of Aqaba than in the Red Sea proper.

The aim of the present study was to identify the mechanisms by which nitrite is accumulated in the Gulf of Aqaba, both in stratified and mixed waters.

\section{MATERIALS AND METHODS}

This study is based on data collected during the Red Sea Programme (January 1997 to January 2000) at the routine station (Stn A) in the Gulf of Aqaba, and includes data collected during the cruise of the German RV 'Meteor' to the Gulf and the northern Red Sea in spring 1999 (Fig. 1).

Water samples were collected by a Rosette sampler with twelve 101 Niskin bottles. Individual water samples were drawn into $14 \mathrm{ml}$ polyethylene test tubes using clean Tygon tubing. For each bottle, the tubing was thoroughly flushed, and each test tube was rinsed 3 times with sample water before filling. Analyses were carried out within $4 \mathrm{~h}$; meanwhile, the samples were kept at $4^{\circ} \mathrm{C}$ in the dark. Nitrite was measured 


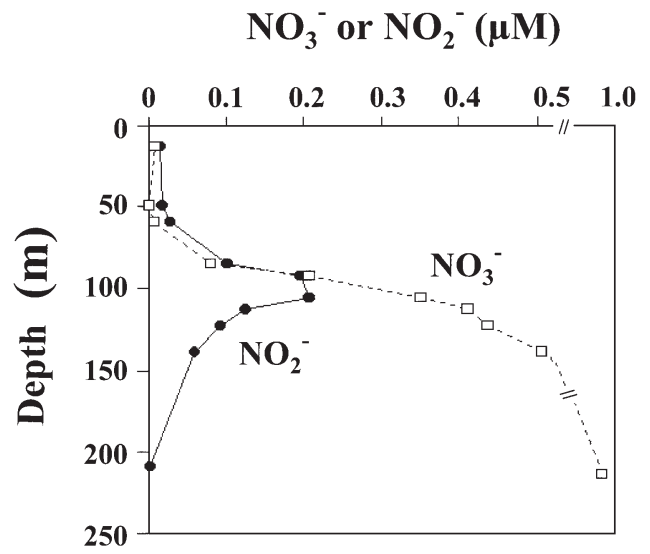

Fig. 2. Examples of typical profiles of nitrite and nitrate during summer stratification in the Gulf of Aqaba at Stn A, 17 July 1998

using a flow injection analyser. After dissociation with sulphanylamide and naphtylethylenediamine, the samples were measured at $550 \mathrm{~nm}$ with filtered seawater as a carrier against a zero blank.

Bioassays were performed by adding nutrients to water samples from the sea surface and from the depth of the deep chlorophyll maximum (DCM; ca. 70 to $90 \mathrm{~m}$ ). Nutrient additions included nitrate and ammonia alone, as well as either nitrate or ammonia together with phosphate. Final concentrations were $6 \mu \mathrm{M}$ N and $0.4 \mu \mathrm{M}$ P, respectively. In addition, nutrient-rich deep $(600 \mathrm{~m})$ water was added to water samples taken from surface and the DCM. During a long-term experiment conducted in September 1999, water samples from the surface and the DCM layer were incubated in situ close to shore at $20 \mathrm{~m}$ depth in natural daylight for $8 \mathrm{~d}$. Short-term experiments ( $24 \mathrm{~h}$ ) were performed at simulated $20 \mathrm{~m}$ light level in basins on board the ship. Temperature was controlled by running surface water. Dark bottles were used as a reference. During the incubation, nitrite concentrations and in vivo chlorophyll fluorescence (as a measure of phytoplankton biomass) were monitored in the experimental flasks.

\section{RESULTS AND DISCUSSION}

Field data. During summer in the stratified water column, ammonia was present and nitrite formed a deep maximum just below the nitracline. During mixing, ammonia concentrations were unexpectedly low, whereas nitrite was homogeneously distributed throughout the mixed layer.

The low ammonium concentration in the mixed layer suggests either rapid transformation of the excreted ammonium into nitrite that accumulates in the mixed layer or rapid uptake of ammonia by phytoplankton. Our field and experimental data clearly support the second assumption.

Nitrite profiles during summer stratification were characterised by nitrite depletion within the upper euphotic zone and a nitrite maximum (up to 0.15 to $0.2 \mu \mathrm{M}$ ) in the waters below (Fig. 2). The DNM was located between 90 and $110 \mathrm{~m}$ depth, which corresponds roughly to the $1 \%$ light depth of PAR. The DNM overlapped with the upper part of the nitracline, but was located below the deep chlorophyll maximum. The shape of the nitrite peak altered little over time, and was somewhat asymmetric, tailing off towards deeper water.

The DNM was established shortly after the onset of stratification in April-May. The maximum nitrite concentration decreased during summer, reaching a minimum towards the end of July. By the end of September, the nitrite concentration had begun to rise again, until the peak was eroded by mixing in November.

Diurnal variations in nitrite and nitrate concentration were recorded on 8 July 1997. Nitrite and nitrate concentrations exhibited marked fluctuations in the uppermost $120 \mathrm{~m}$, which can be attributed to both water movements and biological processes. Regardless of the impact of vertical water motions, the nitrite maximum increased towards evening (Fig. 3). In contrast,
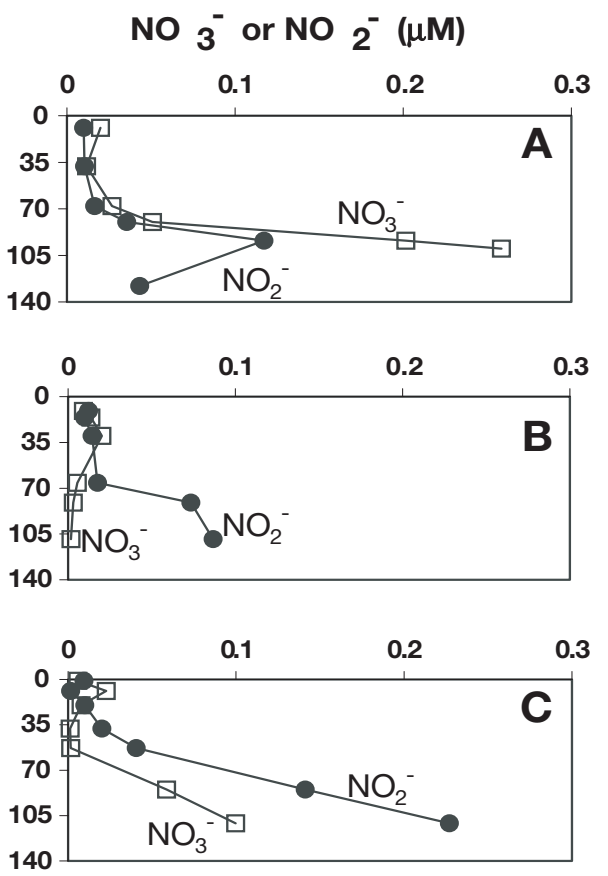

Fig. 3. Vertical nitrite and nitrate profiles observed over $12 \mathrm{~h}$ in the Gulf of Aqaba at Stn A, 8 July 1997, during stratification. (A) Cast finished at 07:30 h local time; (B) cast finished at $12: 00 \mathrm{~h}_{i}(\mathrm{C})$ cast finished at 18:00 $\mathrm{h}$ 


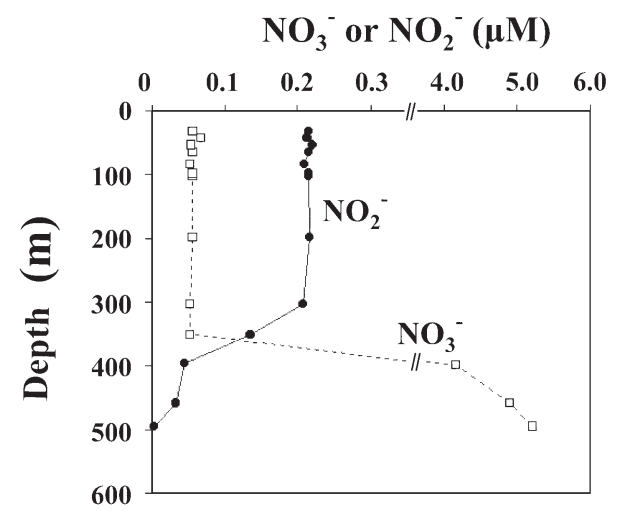

Fig. 4. Examples of typical profiles of nitrite and nitrate during winter mixing in the Gulf of Aqaba at Stn A, 2 February 1998

nitrate concentration decreased in the first half of the daylight period (07:30 to 12:00 h), especially at the bottom of the euphotic zone (Fig. 3). This suggests that nitrate was taken up by phytoplankton cells during that period, and part of it was excreted as nitrite due to nutrient-stimulated growth. Any fluctuation in the nitracline resulting from water motion would only increase nitrate concentration in that region. The increase in nitrate recorded during the second half of the daylight period (12:00 to 18:00 h) is probably related to water motion.

In contrast, during the deep winter mixing, nitrite was homogeneously distributed throughout the mixed layer (Fig. 4). As the mixing deepened, high concentrations of nitrate were entrained into the euphotic zone from deeper water. As a result, phytoplankton growth was stimulated (C. Häse et al. pers. obs.). Concomitantly, the nitrite concentration increased in the mixed layer. This suggests that the accumulation of nitrite in the mixed layer is related to phytoplankton growth, either by release of a small proportion of nitrite generated as an intermediate product of assimilatory nitrate reduction, or by bacterial activity.

\section{Surface phytoplankton}
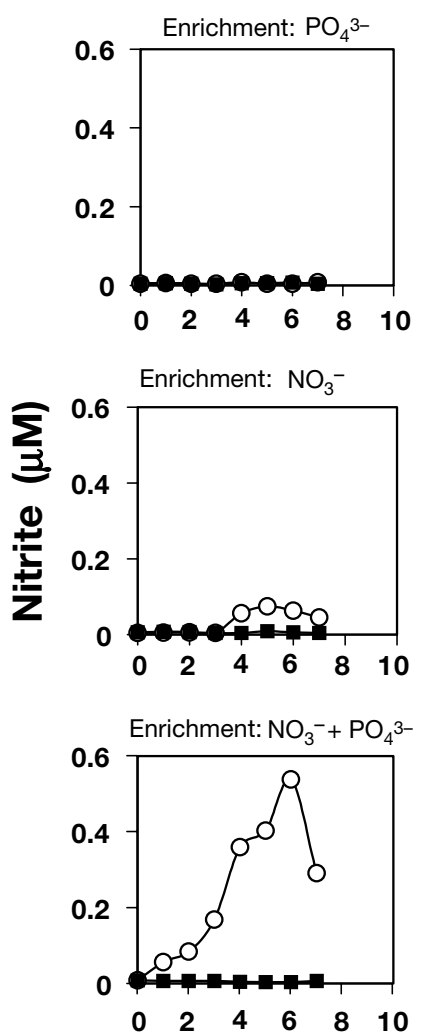
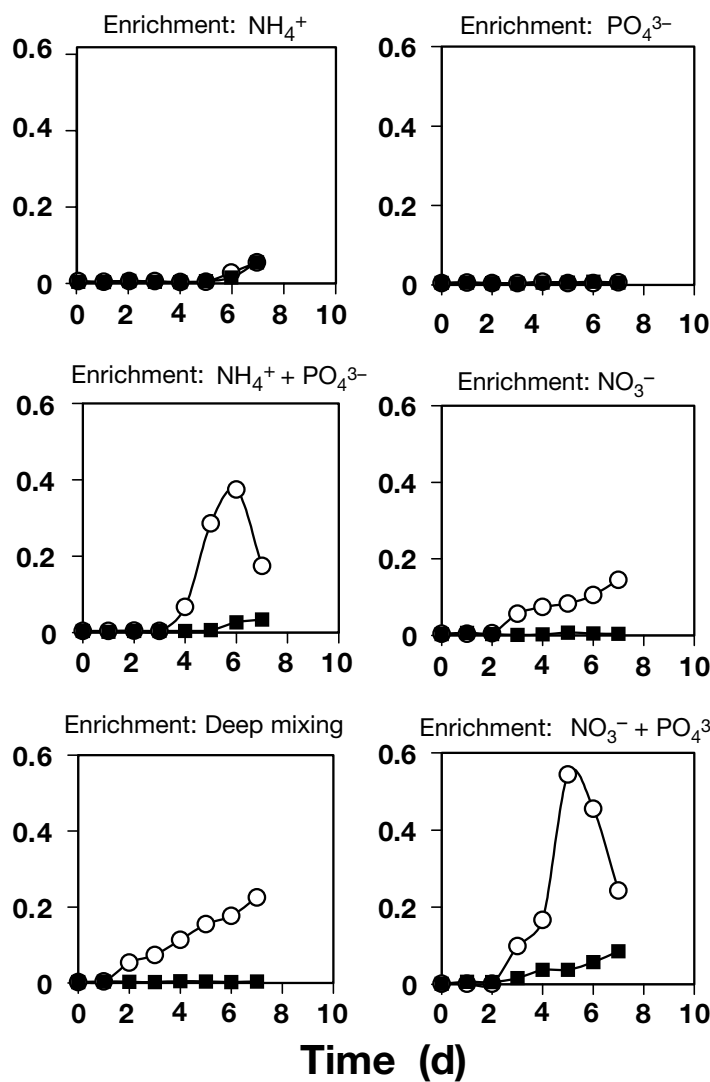
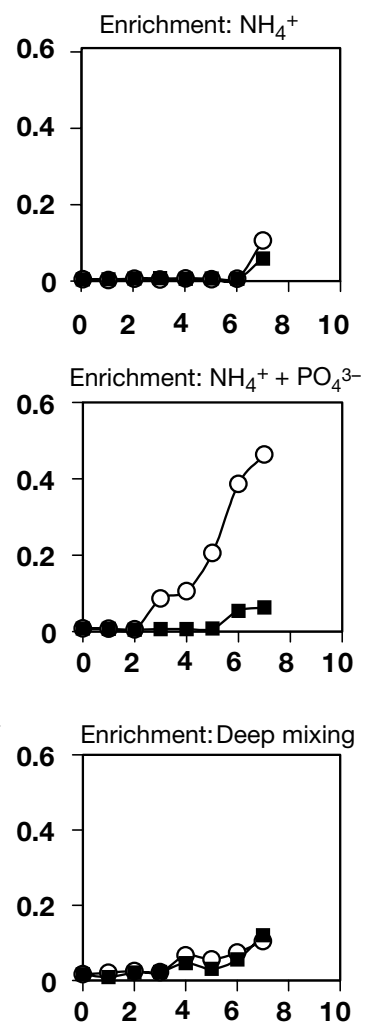

Fig. 5. Time course of nitrite accumulation during $8 \mathrm{~d}$ incubation of the nutrient-enrichment bioassays at Stn A. In light-incubated samples $(O)$ only the addition of either nitrate or ammonia together with phosphate, or deep water, had stimulatory effects on nitrite accumulation, whereas neither nitrate nor ammonium alone elicited any response. Dark-incubated samples ( $\mathbf{\square})$ did not show any response. Experiment began on 7 September 1999. DMC: deep chlorophyll maximum 
Bioassay experiments

In the bioassays, nitrite accumulation was observed only when the samples were enriched with both $\mathrm{N}$ and $\mathrm{P}$ in samples incubated in the light (Fig. 5) (M. Al-Qutob et al. pers. obs.). In contrast, little or no increase was observed in the nitrite concentration after additions of nitrate, ammonium or phosphate alone. Nitrite concentration changes exhibited patterns similar to the development of the phytoplankton biomass (Fig. 6).

Because nitrite release was only observed after additions of both $\mathrm{N}$ and $\mathrm{P}$, we conclude that phytoplankton growth plays the key role in nitrite accumulation within the mixed water column. Our experiments clearly indicate that nitrite is accumulated as a result of phytoplankon growth, which needs light and both a nitrogen and a phosphate source.

Our bioassays strongly suggest that the accumulation of nitrite during mixing was coupled to the development of phytoplankton biomass. At the present stage, the underlying mechanism cannot be finally resolved. Indirect coupling could include either excretion of DOM by phytoplankton or grazing and/or decomposition of organic matter, all of which support bacterial growth. However, the bioassays give strong evidence of direct coupling: (1) No consumption of the added ammonium could be observed within the first few days of the long-term experiment; (2) phytoplankton growth and nitrite accumulation occurred simultaneously; (3) nitrite concentrations decreased in parallel with phytoplankton biomass towards the end of the incubation.

In the bioassays the final concentrations of the added nutrient salts were $6 \mu \mathrm{MN}$ and $0.4 \mu \mathrm{MP}$. In addition, nutrient-rich deep $(600 \mathrm{~m})$ water was added to surface and DCM-water, leading to a final concentration of $\sim 1 \mu \mathrm{MN}$. After total consumption of the nitrate and phosphate, the former samples contained up to $0.6 \mu \mathrm{M}$ of nitrite in the incubation bottle, and the latter up to $0.2 \mu \mathrm{M}$, implying that 80 to $90 \%$ of the nitrate taken up by the phytoplankton was incorporated into biomass, and 10 to $20 \%$ was excreted as nitrite. In a year with a typical maximum winter mixing depth of $400 \mathrm{~m}$, a total of about $800 \mathrm{mmol}$ nitrate is entrained into the mixed layer. This corresponds to an average nitrate concentration within the $400 \mathrm{~m}$ mixed layer of about $2 \mu \mathrm{M}$.
Surface Phytoplankton

\section{DCM Phytoplankton}
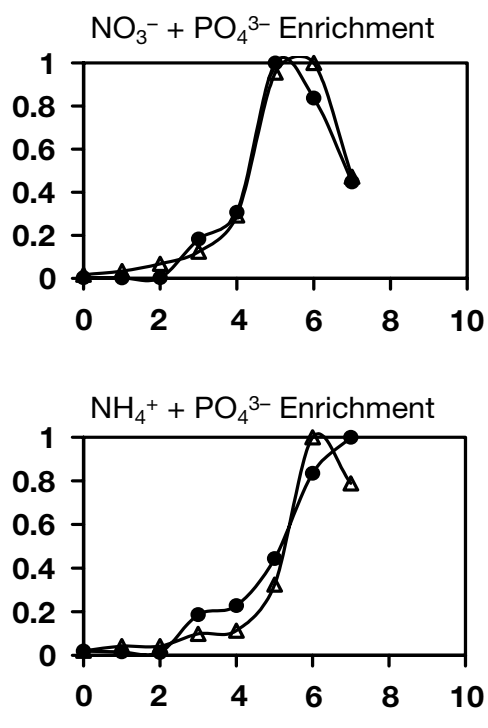

Deep water enrichment
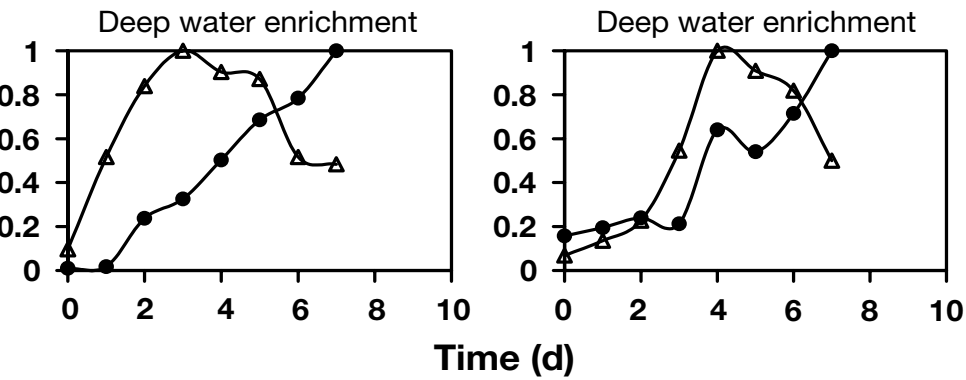

Fig. 6. Time course of nitrite concentrations $(\bullet)$ and in vivo fluorescence $(\Delta)$ during $8 \mathrm{~d}$ incubation of the nutrient enrichment bioassays. Only results from assays with dual additions of $\mathrm{N}$ plus $\mathrm{P}$ are shown, since single additions did not elicit any response

The maximum concentration of nitrite in the mixed column reached 0.2 to $0.3 \mu \mathrm{M}$ towards the end of the mixing season. This confirms that between 10 and $15 \%$ of the total amount of nitrate introduced into the mixing column was released as nitrite by the phytoplankton cells in situ, the same proportion as in the bioassays. We would emphasise that this amount of nitrite accumulated is the net result of nitrate entrained or enriched on the one side and nitrite accumulated and consumed by bacteria (or even certain phytoplankton species) on the other. After the mixing has stopped, nitrite is completely assimilated from the water column, since new nitrate is no longer entrained.

Nitrification was recently reported to play an important role in nitrogen recycling within the euphotic zone of oligotrophic oceans (Ward et al. 1989, Dore \& Karl 1996b). In particular, high ammonia oxidation rates were measured below the DNM peak, whereas above the DNM peak, nitrite release by phytoplankton was a 
significant source of nitrite (Wada \& Hattori 1971, Dore \& Karl 1996b). However, in our bioassays, nitrite accumulation due to nitrification was low, as evident from the dark samples enriched solely with ammonia (Fig. 5). Likewise, nitrite accumulation was quicker in samples with nitrate + phosphate than with ammonia + phosphate additions, indicating that nitrite production from ammonia via nitrification plays only a minor role during mixing. This, and the diurnal dynamics of nitrite and nitrate concentrations (Fig. 3), give strong evidence that during stratification in summer nitrite excretion by phytoplankton does contribute a significant share to the formation of the DNM in the Gulf of Aqaba.

Nitrite release by phytoplankton during nitrate assimilation has been reported by several authors (Vaccaro \& Ryther 1960, Wada \& Hattori 1971, Collos 1998). However, to our knowledge, this is the first time that nitrite release by phytoplankton is reported for phytoplankton growth stimulated by addition of ammonia. Unlike nitrate, ammonia does not have to be reduced to be incorporated into biomass. Therefore, we conclude that the nitrite released in the bioassays, especially in those with ammonia plus phosphate additions, was not directly related to nutrient assimilation of the algal cells. Thus, a different and so far unrecognised physiological pathway must be responsible.

\section{CONCLUSIONS}

The nutrient-enrichment bioassays were performed at the end of the stratification period. At this time, nitrite in situ was only present in the deep nitrite maximum below the deep chlorophyll maximum. The results of the bioassays are summarized as follows: (1) Nitrite accumulated in remarkable concentrations only in light samples, not in dark samples; (2) only the addition of both nitrogen and phosphate had stimulatory effects on nitrite accumulation, whereas neither nitrate nor ammonium alone elicited any responses; (3) nitrite accumulation closely paralleled the development of phytoplankton biomass with no time lag, and especially did not occur in those bioassays that showed no change in phytoplankton biomass; (4) surface and DCM samples responded similarly; (5) accumulation was faster in samples with nitrate + phosphate than with ammonia + phosphate additions, indicating that nitrite production from ammonia via nitrification plays only a minor role during mixing.

These results, together with the field data, clearly support the hypothesis that nitrite accumulation during mixing is driven by nutrient-replete phytoplankton growth.
Both field and experimental data have shown that about 10 to $20 \%$ of the $\mathrm{N}$ introduced into the mixed layer by deep winter mixing is released as nitrite. This process is dependent on phytoplankton photosynthesis, as no nitrite accumulated in the bioassays performed in the dark.

Field and experimental data support the hypothesis that nitrite excretion by phytoplankton has a significant role in the formation of the DNM during stratification in summer.

Finally, our results indicate that there is a so far unrecognised physiological pathway involved in nitrite excretion by phytoplankton cells.

Acknowledgements. We are grateful to the coordinator of the Red Sea Program, G. Hempel. We are also grateful for helpful comments on this manuscript from Z. Dubinsky, J. Erez, N. Stambler and 3 anonymous reviewers. We thank M. Dray and R. Shem-Tov for their support with sampling and logistics. We also would like to thank the captains and the crew of the research vessels 'Meteor', 'Suellyn' and 'Sea Surveyor' and all the members of the Red Sea Program project. This work was supported by the German Ministry for Education and Research (BMBF) within the Red Sea Program. This work was part of the PhD thesis of M.A-Q. at Bar Ilan University, Israel.

\section{LITERATURE CITED}

Brandhorst W (1959) Nitrification and denitrification in the eastern tropic North Pacific. J Cons Perm Int Explor Mer 25:2-20

Collos Y (1998) Nitrate uptake, nitrite release and uptake, and new production estimates. Mar Ecol Prog Ser 171: 293-301

Dore JE, Karl DM (1996a) Nitrite distributions and dynamics at station ALOHA. Deep-Sea Res 43:385-402

Dore JE, Karl DM (1996b) Nitrification in the euphotic zone as a source for nitrite, nitrate and nitrous oxide at station ALOHA. Limnol Oceanogr 41:1619-1628

Enoksson V, Fogelqvist E, Fonselius S (1996) Nitrogen speciation and nitrification potential in the Skagerrak area during the SKAGEX IV experiment. Deep-Sea Res 43: 1029-1044

Guerrero MA, Jones RD (1996) Photoinhibition of marine nitrifying bacteria. I. Wavelength-dependent response. Mar Ecol Prog Ser 141:183-192

Herbland A, Voituriez B (1979) Hydrological structure analysis for estimating the primary production in tropical Atlantic Ocean. J Mar Res 37:87-101

Horrigan SG, Carlucci AF, Williams PM (1981) Light inhibition of nitrification in sea surface films. J Mar Res 39: $557-565$

Kiefer DA, Olson RJ, Holm-Hansen O (1976) Another look at the nitrite and chlorophyll maxima in the central North Pacific. Deep-Sea Res 23:1199-1208

Lipschultz F, Zafiriou OC, Ball LA (1996) Seasonal fluctuations of nitrite concentration in the deep oligotrophic ocean. Deep-Sea Res Part II 43:403-419

Miyazzaki TE, Wada EA, Hattori (1973) Capacities of shallow waters of Sagami Bay for oxidation and reduction of inorganic nitrogen. Deep-Sea Res 20:571-577 
Miyazzaki TE, Wada E, Hattori A (1975) Nitrite production from ammonia and nitrate in the euphotic layer of the western North Pacific. Mar Sci Commun 1:381-394

Olson RJ (1981a) ${ }^{15} \mathrm{~N}$ tracer studies of the primary nitrite maximum. J Mar Res 39:203-226

Olson RJ (1981b) Differential photoinhibition of marine nitrifying bacteria: a possible mechanism for the formation of the primary nitrite maximum. J Mar Res 39: $227-238$

Rakestraw NW (1936) The occurrence and significance of nitrite in the sea. Biol Bull 71:131-167

Vaccaro RF, Ryther JH (1960) Marine phytoplankton and the

Editorial responsibility: Gotthilf Hempel,

Bremen, Germany distribution of nitrite in the sea. J Cons Int Explor Mer 25: $260-271$

Wada E, Hattori A (1971) Nitrite metabolism in the euphotic layer of the central North Pacific Ocean. Limnol Oceanogr 16:766-772

Ward BB (1986) Nitrification in marine environments. In: Prosser JI (ed) Nitrification. IRL Press, Oxford, p 157-184

Ward BB, Kilpatrick KA, Renger EH, Eppley RW (1989) Biological nitrogen cycling in the nitracline. Limnol Oceanogr 34:493-513

Zafiriou OC, Ball LA, Hanley Q (1992) Trace nitrite in oxic waters. Deep-Sea Res 39:1329-1347

Submitted: May 3, 2001; Accepted: January 31, 2002

Proofs received from author(s): August 7, 2002 